attempted to discuss may well be adapted to use in private practice without change of material importance. It has been the method followed by the author for eleven years in private practice and the results obtained have proven the reliability and dependability of the objective method of refraction. My associates in the Attending Surgeon's Office have adopted this method of objective refraction; and with the opportunity offered for observing the final results obtained in the refractions performed in this office, it may be said in all fairness that the objective method of determining and correcting errors of refraction has proven itself to be superior in every respect to subjective methods. The proof has been so convincing and conclusive that all subjective methods have practically been clicarded, and the refraction work of the Department of Ophthalmology of The Attending Surgeon's Office is based entirely upon objective methods.

\title{
FUNDUS PATHOLOGY WITH THE RED-FREE LIGHT OF VOGT.
}

\section{ROUERT VON DER HFYDT, M.D. \\ CIICARO, ILIINOIS}

This paper calls attention to (a) A new Symptom of Retinal Atrophy, and (b) Macular and Foveal Changes. With illustrations showing the apparatus used to furnish the tight. Read before tile Chicago Ophthalmological Society, February 17. 1919. (See p. 351 for Discussion.)

In the normal fundus the red-free light gives us the first absolute demunstration of the ycllow coloring at the

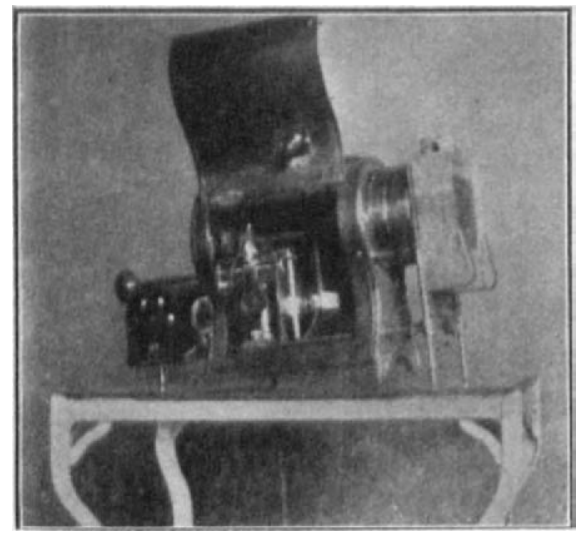

Fig. 1. Jamp with filtration apparatus, after Vogt and Affolter.

macula in the living eye. (Owing to an increased contrast new details of the macula and forea can be seen.

With it we can also measure by comparison the yellow discoloration of the lens in age and in monolateral aphakia.

In adllition the increased visibility of the retinal nerve fibers with the redfree light is of great importance. In a recent article Vogt draws attention to the fact that optic atrophy with our prescut method of examination is only diagnosible at the nerve-head and from the vessel caliber of the same. The retima, however, though it no doubt is regularly involved in the atrophic process. slows no ophthal moscopic changes. With the red-free light he is able to see the nerve striations of the retina and stucly their pathologic changes.

In nptic neuritis and retinitis the nerve tibers are coarser, single bundles intermingle, while elsewhere they are interrupted and scem to recede in steplike layers.

Asicle from these inflammatory changes he finds certain modifications of the nerve fiber striations in optic atrophy, In complete postneuritic, as well as in primary and glaucomatous atrophy, also in that complicating retinitis pigmentosa and fracture of the base of the skull, there is found a white, marble-like mottling of the surface.

Most interesting and instructive are the cases where one optic nerve is normal and the other atrophic. 
1 case of this type, following fracture of the base of the skull, five years ago, in a male, now forty-five vears of ige, is described.

With the ordinary illumination there are no changes except those of atrophy at the nerve-head and its vessels. With the red-frec light, however, we find a total absence of the rotinal striations in the atrophic eye. In their place there is a delicately motted marbleized surface. Nlso, a thin, whitisl line on either sicle of the vessels, invisible with ordinary illumination. In a case of partial postneuritic atrophy complicating multiple sclerosis there was a reduction in the risibility of the nerve

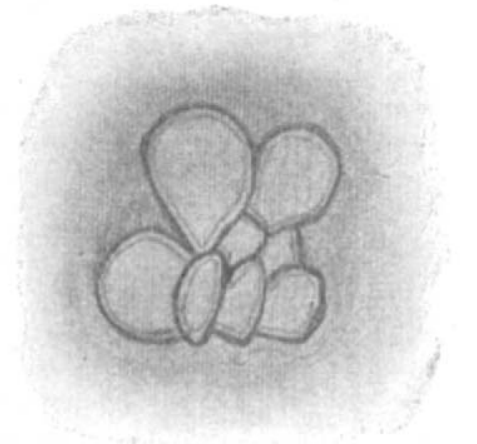

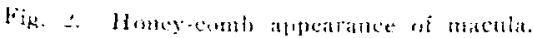

libre striac, and in certain zones they mere absent.

This herewith described disappearances of retinal striations must lice added to the symptomatology of optic atrophy, and must be conceded to be the only known visible ophthalnoscopic sign of retinal atrophy, if we ex- Wucle the more or less inclefinite picture "if shrinking of the ressel caliber. ()f especial practical importance are further detailed observations made with the revi-fres light in retrobulhar netritis.

In the diagnosis of this quite conmon and often obseure eye discase, 110 must at times make absolute dependence on such subjective symptoms as the statement of the patient as to his habits, nyetalopia, central scotoma, etc

Several authors have drawn attention to degenorative changes in the retinal vessels which accompany this discase. They are, however, not always present and of ten difficult of diagnosis. If present they are not necessarily pathognomonic of retrobulbar neuritis. The latter is also true of the su-called temporal pallor of the disc, which is often found in normal fumdi.

It is therefore of ereat practical value that we have in the red-iree illumination a method at our disposal with which we can diagnose degenerative changes of the maculopapillary bundle in retrobulbar neuritis.

The changes found with great regularity (eight cases) are the above described absence of striation and a substitution therefor of the marbleized zone in the papillomacular bundle.

Vogt has been able to observe similar changes and degencrations in this same retinal zonc in cases of ascending atrophy of this central nerve tract in isolated disease, and degeneration of the macular and foreal zone.

lery recent anatomic investigalioms have proven that the macular zone is practically absent in the cyes of Albinos. The investigations of logt and Affulter seem to confirm this as they fail to find the yellow coloration at the macula in the eyes of living Mhinos. This learls to the conclusion that the absence of the ycllow coloring matter deposited in the mactila is in direct or indirect relation to the lack of pigment in gencral.

In the past fow months I hare been able to study many fundi with the redfree light. The yellow coloration of the macula is most beautiful. I note a greatly increased visibility of the foreolar reftex of Dimmer. It shows as a most luminous spot, much nore sistening, for instance, than any socalled cholesterin crystals I have ever seens.

Further investigation in this zone with the red-free light I an stre will make of greater value the work of Haab. Dimmer, Gullstrand, and others who have made this physiologically so important, and pathologically most ruhemale retinal area, the object of 
so much observation, study and research.

Vogt describes certain pathologic honeycomb-like changes of the macula, visible only in the red-free light. They were found especially in cases of retinitis pigmentosa, and continued during certain long periods. A year later, in one case, he found them less marked. In othcr very advanced cases they were absent.

Vogt also has noted this vacuoli formation, for a period of several months, in cases of injury to the macula following contusion of the bulb. Later on they gradually disappeared.

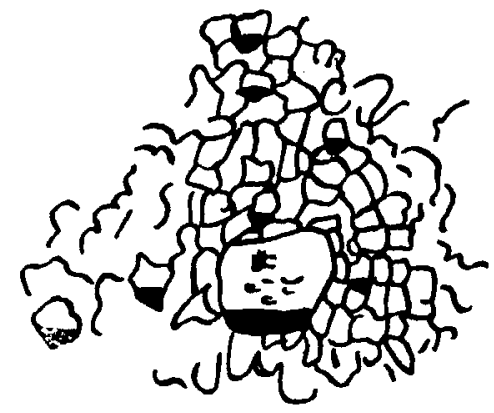

Fig. 3 gravitate to the altered position. On the patient's resuming the upright attitude they would return to their original site in about two minutes.

Following this experiment a distinct clouding of the clear contents of the cyst above the hyphema was repeatedly noted and continued for a short period, due to a whirling or stirring up of the pigment disturbed in its complete precipitation.

All of these observations prove that cystic degeneration of the macula can produce the condition we call "hole in the macula," and account for the great length of time so often consumed in

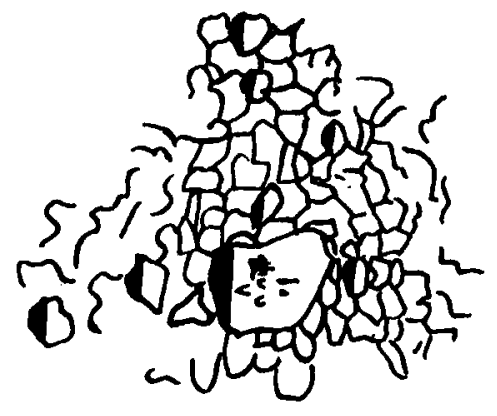

Fig. 4

fiffect of change of posture showing gravitation of hyphemae.

He considers them symptoms of valscular and cystic degeneration of the macutla.

Leber has described similar vacuoles of the macula anatomically and presumes that the bursting of some of the ir thin anterior walls could produce, in time, the condition we know of as "hole in the macula."

Vogt gives a most interesting description of vacuoles of this kind in a case of embolism of the central retinal vein. Tiwo large, nearly circular, spaces in the center of the macula showed a hyphema in their lower thirds. After a few days these two became confluent. Quite a number of other smaller vacuoles, partly containing blood, were visible and remained so for months. If the patient would be examined lying on one or the other side, this precipitate would slide or gradually bringing about this intercsting pathologic condition.

Many new reflexes in various parts of the retina and true folds not due to separation or detachment are fully described by Vogt in several recent articles. Affolter also emphasizes the greater visibility of delicate vitreous opacities, deposits on lens and vascularization of the cornea, with the redfree light.

It is not expected that this method will supersede the ordinary light for ophthalmoscopy. Certain conditions, such as exudative zones, the changes of retinitis proliferans, medullated nerve fibers, and the star figuration of retinitis, for instance, are scen in better contrast with our old light. There is 110 cloubt, however, that with the redfree light we have added a most valuable and helpful method of diagnosis. 